\title{
The prevalence of computer game addiction and related factors in male adolescent of Gonabad in 2018
}

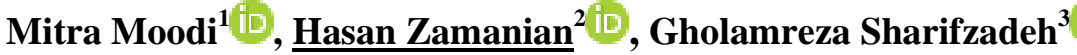 \\ ${ }^{1}$ Social Determinants of Health Research Center, Department of Health Education and Health Promotion, Birjand University of \\ Medical Sciences, Birjand, Iran. \\ ${ }^{2}$ Student Research Committee, Department of Health Education and Health Promotion, Social Determinants of Health Research \\ Center, Birjand University of Medical Sciences, Birjand, Iran. \\ ${ }^{3}$ Social Determinants of Health Research Center, Department of Public Health, Faculty of Health, Birjand University of Medical \\ Sciences, Birjand, Iran.
}

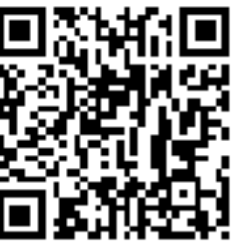

Citation Moodi M, Zamanian H, Sharifzadeh Gh. [The prevalence of computer game addiction and related factors in adolescent boys of Gonabad in 2018]. J Birjand Univ Med Sci. 2020; 27(2): 191-200. [Persian]

DOI http://doi.org/10.32592/JBirjandUnivMedSci.2020.27.2.107

Received: September 4, 2019

Accepted: October 16, 2019

\begin{abstract}
Background and Aim: Computer games are a kind of growing and attractive new communication technology. This has prompted researchers to study the effects of these games on users. This study was performed aimed to determine the prevalence of computer game addiction and related factors in male adolescent boys of Gonabad in 2018.

Materials and Methods: In this descriptive-analytical cross-sectional study, 507 male students of the first-grade in Gonabad were examined by multi-stage sampling method. Data collection tools were included in two sections: Demographic information and the Lummens Computer Games addiction questionnaire. The data were analyzed by using SPSS software (Version 19) with the help of the Chi-square and Fisher's exact test.

Results: The average age of the students in this study was $13.5 \pm 1$ years. The most popular feature of computer games is a lot of excitement (42\%), competitive games (29\%) and the most common types of computer games were football (48.9\%) and violent games $(21.7 \%) .28 .4 \%$ of students went to Game Center to play computer games. The prevalence of dependence on computer games was moderate to high $(73.2 \%)$ It showed a significant relationship with the level of education of the mother $(\mathrm{P}=0.03)$, playing computer games by the parents $(\mathrm{P}<0.001)$ and the educational level of the students $(\mathrm{P}=0.04)$.
\end{abstract}

Conclusion: The results showed that the highest level of dependence of students was at the intermediate level, which indicates the importance of the problem and the need for the authorities to intervene in this field.

Key Words: Addiction, Computer Game; Male Adolescent; Prevalence; Student 


\section{شيوع وابستكى به بازىهاى رايانهاى و عوامل مرتبط با آن در

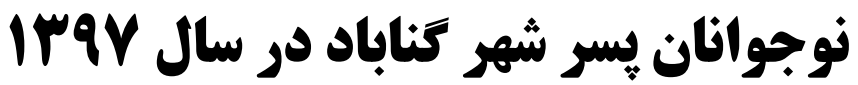

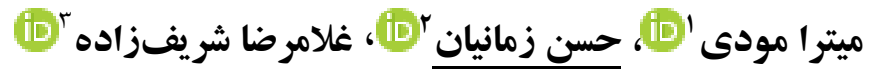

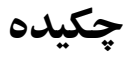

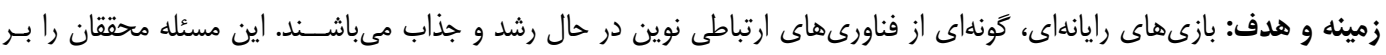

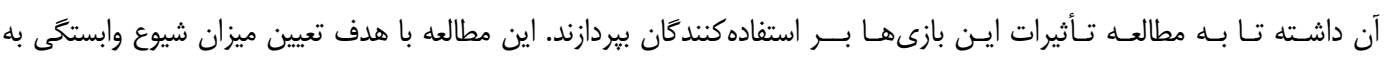

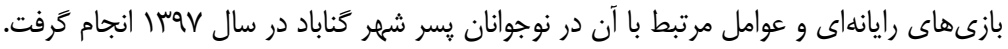

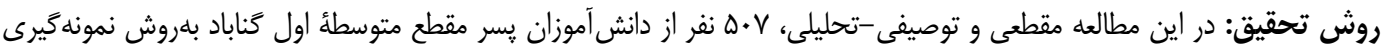

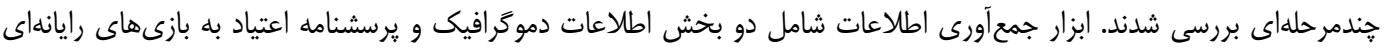

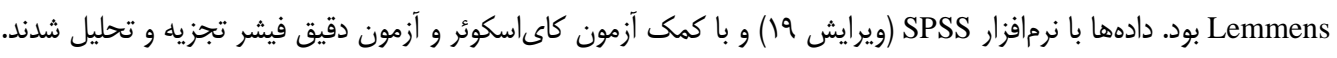

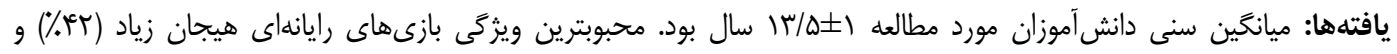

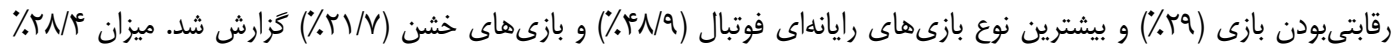

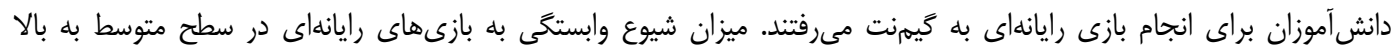

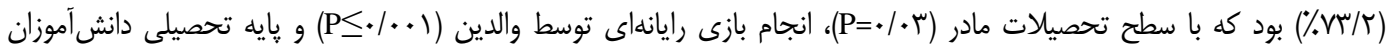

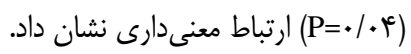

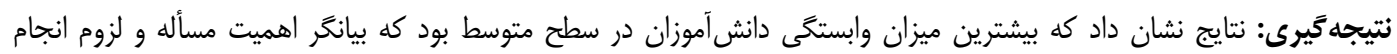
مداخلات در اين زمينه توسط مسئولين مىباشيد. وازههاى كليدى: اعتياد؛ بازى رايانهاى؛ پِس نوجوان؛ شيوع؛ دانش آموز

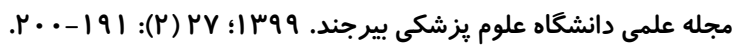

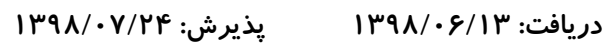

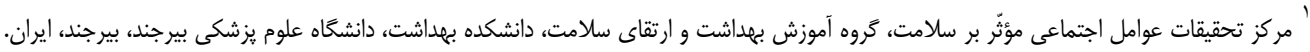

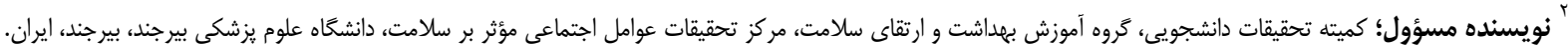

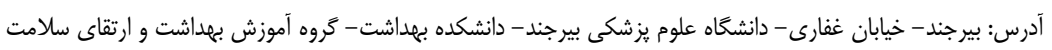

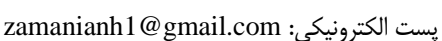

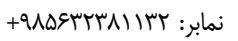
تلفن: INDIQVTD+KII

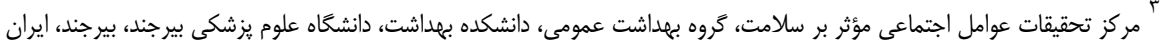


يبيجيدگى احساس نياز، تشويق دوستان، ميل به رقابت و مقل مله

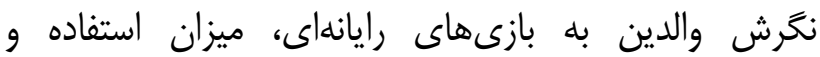

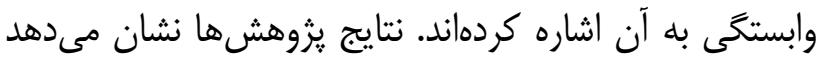

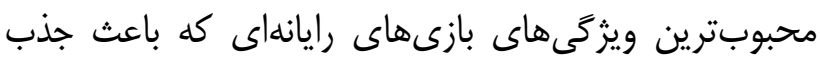

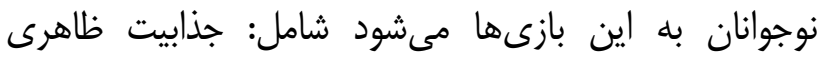

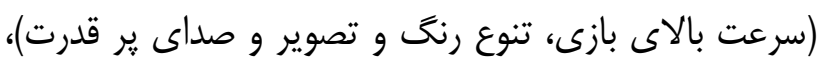

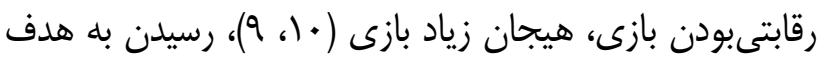

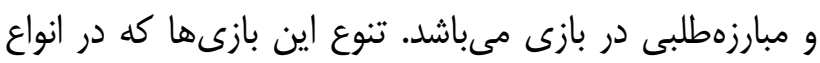

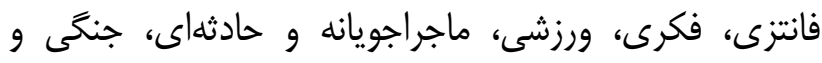

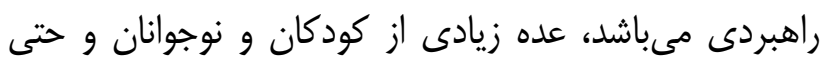

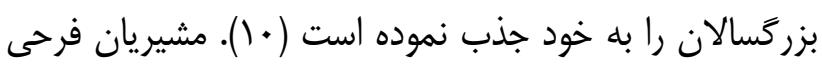

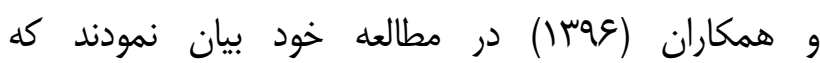
آيارتماننشينى، تكفرزندى، شاغلبودن يدر و مادر، استفاده

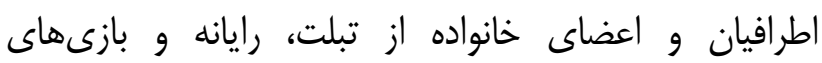

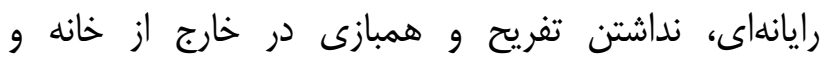

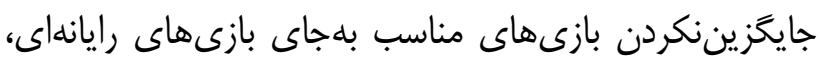

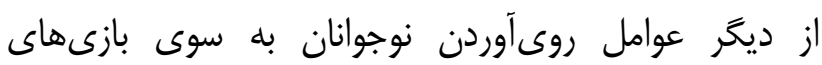
رايانهاى است (9).

كزارش مركز تحقيقات بازىهاى ديجيتال در ايران (سال

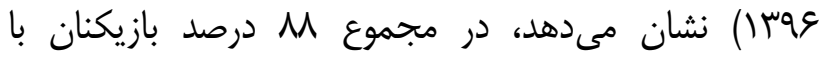

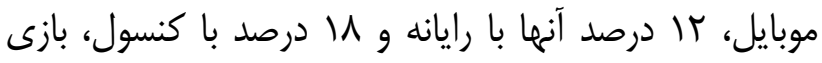

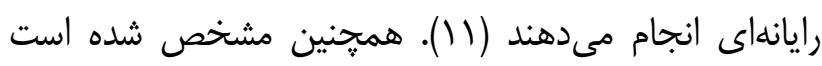

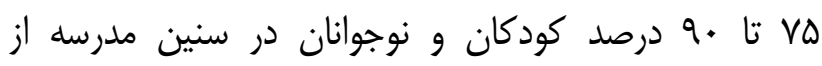

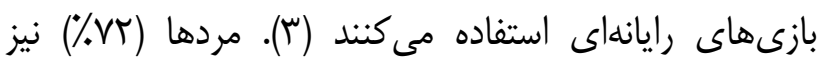

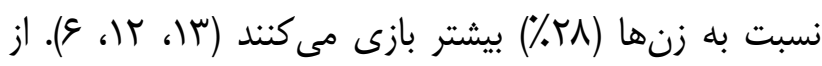

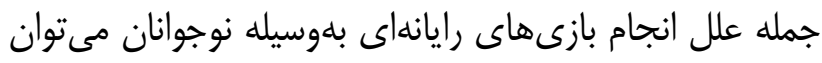

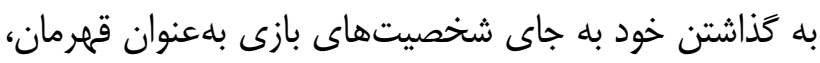

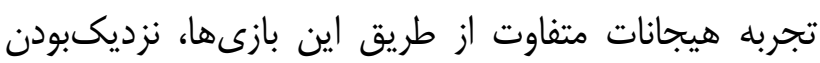

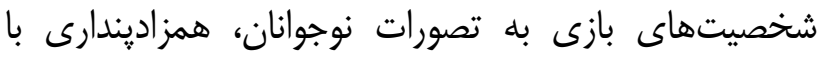

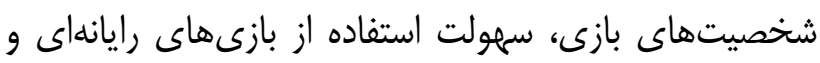

نياز نداشتن به وسايل بازى و همبازى اشاره نمود (9).

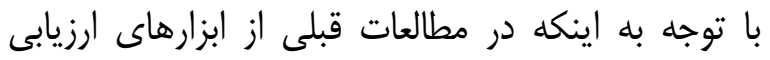

با رشد فناورىهاى اطلاعاتى و ارتباطاتى در عصر حاضر

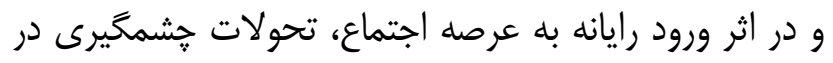

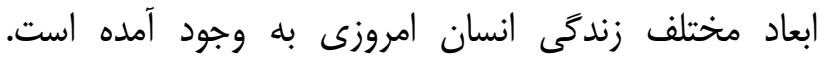

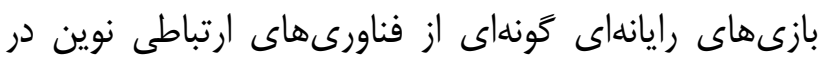

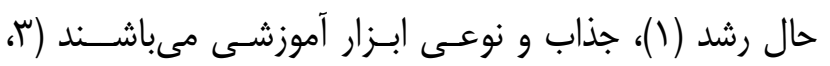

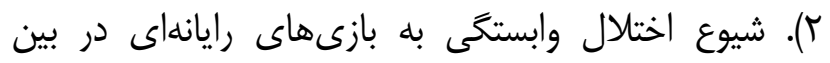

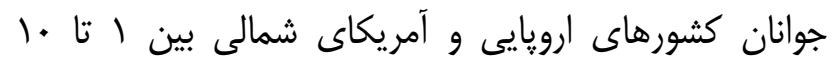
درصد، در بين كشورهاى آمريكاى جنوبى و آفريقا بين آنائ آتان

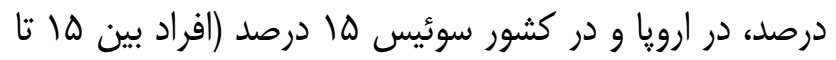
1.

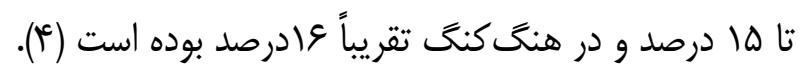

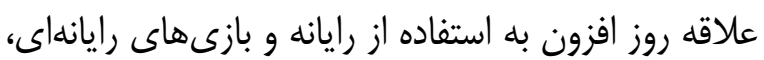

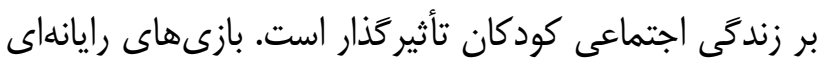

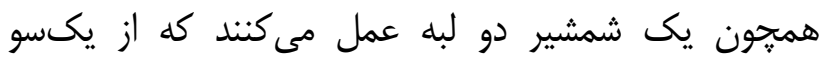

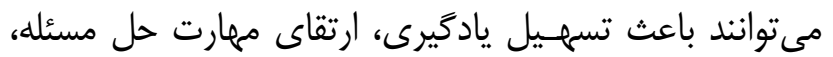

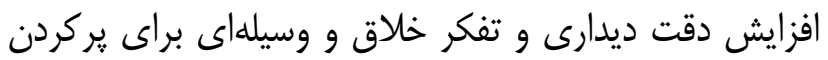
اوقات فراغت كودكان و نوجوانان باشند (َّ) و از سوى ديخر دئر

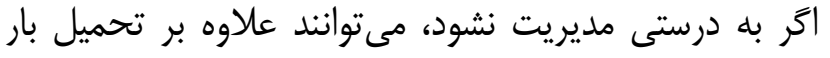

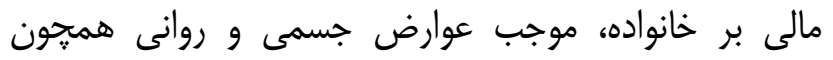

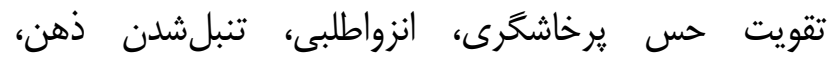

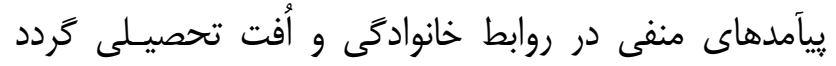
(ه). از مهمترين بيامدهاى منفى روانى - اجتماعى بازى دهاى

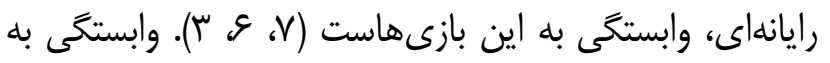

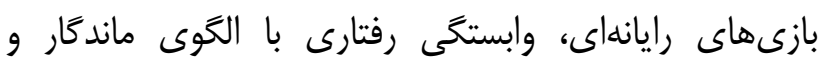
ناساز كار است و در طيف اختلالات وسواسى - اجبارى قرار

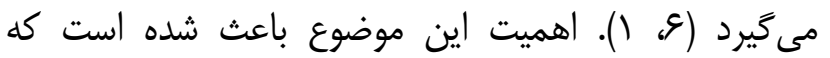
سازمان جهانى بهاشت، اختيران

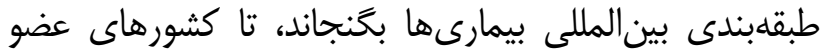

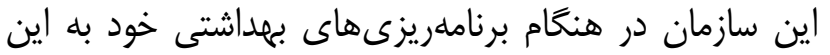

مهم توجه نمايند (1).

يزوهشهاى مختلفى به رابطه بين جذابيت، تنوع و 
روش تحقيق مطالعه حاضر يك مطالعه توصيفى - تحليلى از نوع

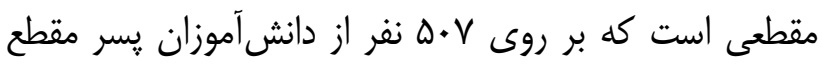

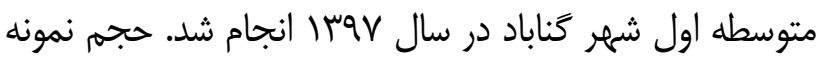

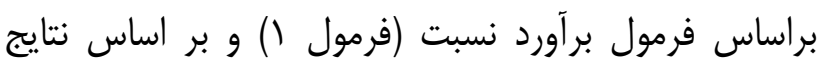

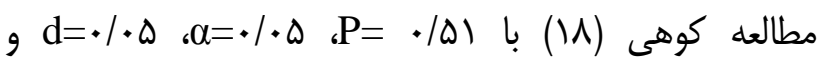

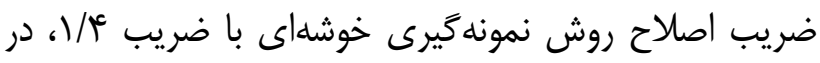
تعداد VWه نفر برآورد شد.

فرمول (1): - 20 - (1)

$$
\mathrm{n}=\frac{\mathrm{z}^{\mathrm{z}} \mathrm{pq}}{\mathrm{d}^{\mathrm{z}}}
$$

ابزار جمعآورى اطاعات در دو بخش تنظيم شده بود:

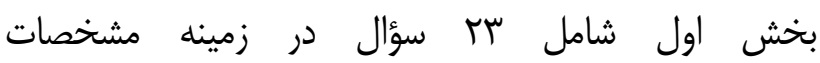
جمعيتشناختى (شامل: سن دانشآموز و والدين، شغل ثيدر،

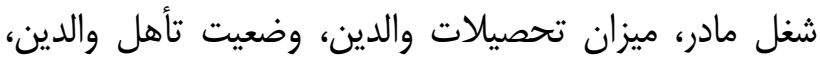

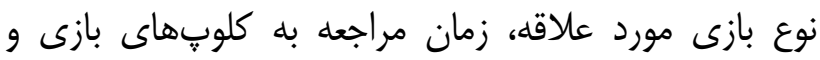

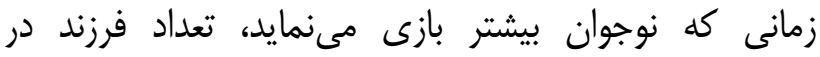

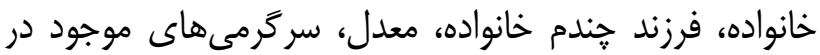

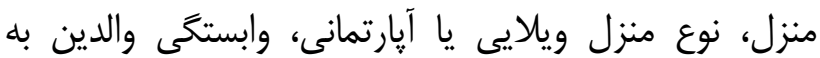

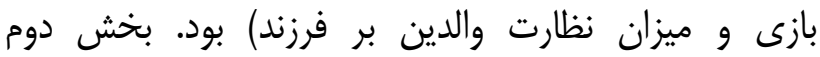

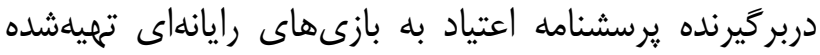

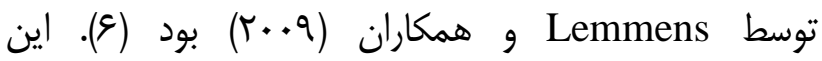
يرسشنامه كه آ سؤال دارد، ميزان وابستخى نوجوانان به به بازىهاى رايانهاى را در طول شش ماه كذشته مىسنجاه

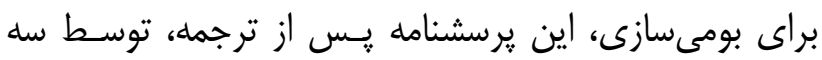

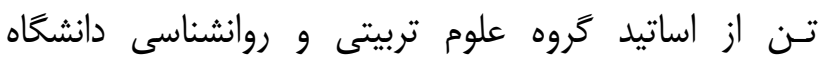

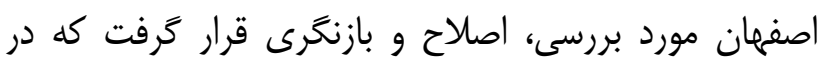

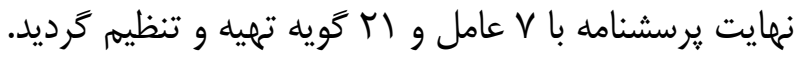

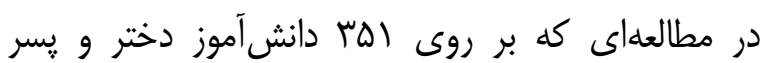
مشغول به تحصيل در يايه اول دبيرستان اصفهان انجام شده دهاء

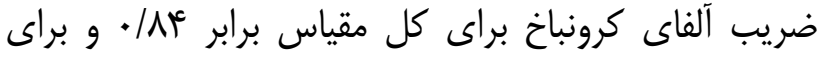

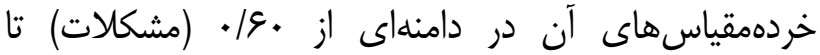

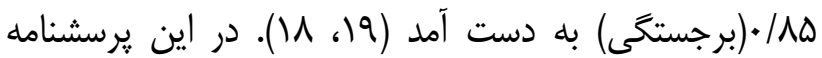

متفاوتى استفاده شده و گروههاى شركت كننده متنوعى را دربر

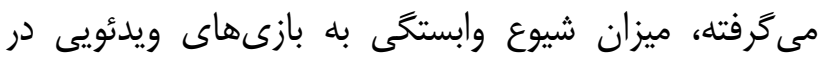

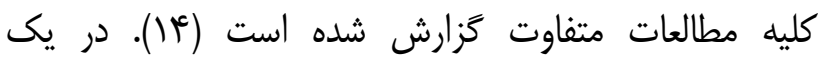
نظرسنجى در آمريكا نشان داده شده است كه لو نوجوانان IV-IV ساله، بازىهاى ويدئويى انجام ميدهند. مطالعات شيوع بيانكر اين مطلب است كه شيوع اختلال بازل

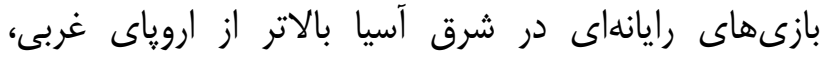

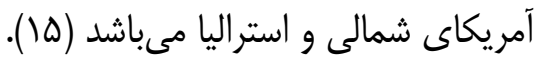

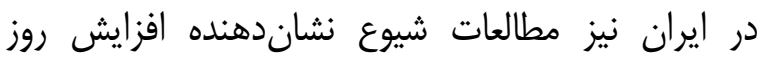

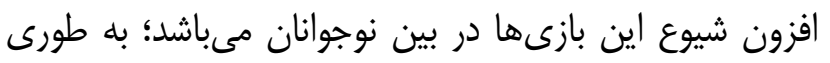

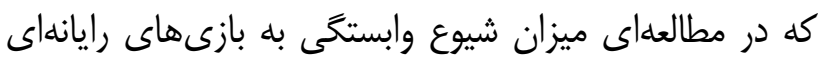

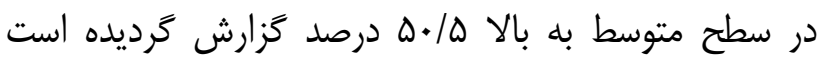

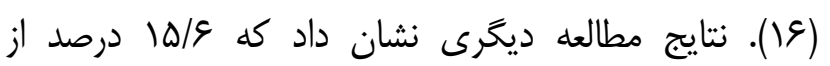

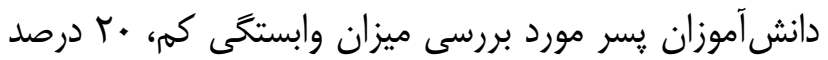

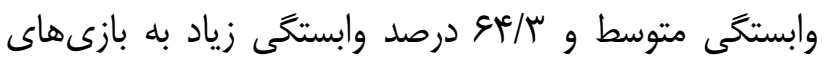

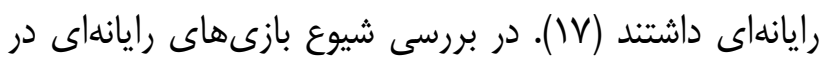
بين نوجوانان زنجان به تفكيك جنسيت، شيوع اين بازىها در

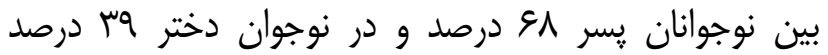

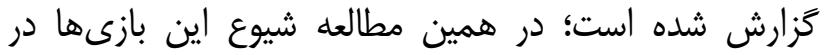

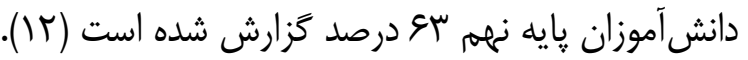
با توجه به شيوع روز افزون بازىهاى رايانهاى در بيه بين نوجوانان و اينكه دانشآموزان بلعنوان سرمايههاى هر كشور أنون بازي محسوب مىشوند، لازم است مطالعاتى در اين زمينه انجام

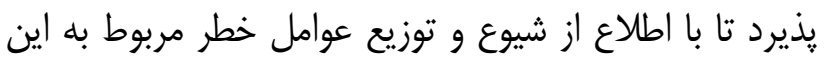

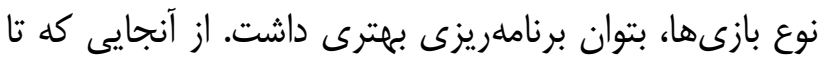

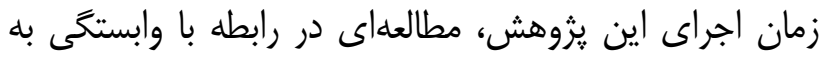

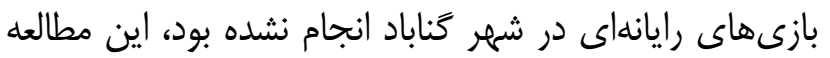

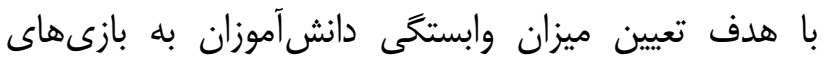
رايانهاى و عوامل مرتبط با آن صورت كرفت مين. 
مقطع متوسطه دوره اول قرار داده شد. بdمنظور رعايت ملاحظات اخلاقى، ابتدا هدف از انجام

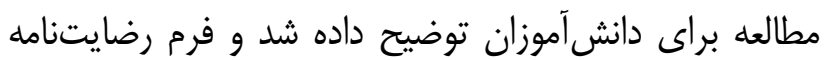

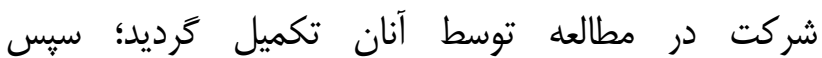
يرسشنامهها بدون ذكر اسامى افراد بلهورت خودايفا توسط

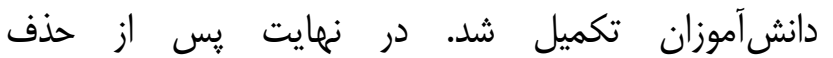

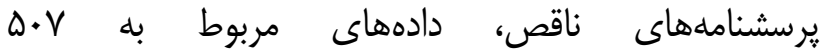

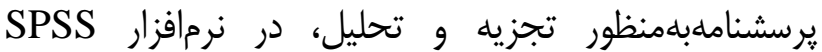
(ويرايش 19) وارد گرديد. دادهها با استفاده از آزمونهاى دراى

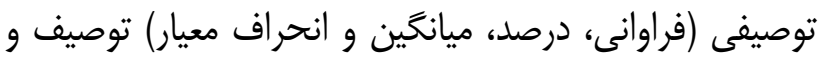

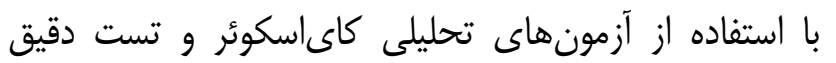

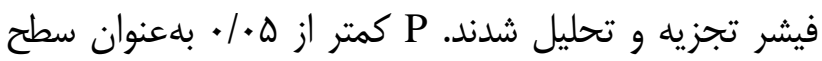
معنى دارى در نظر گرفته شد.

يافته ها

اين مطالعه بر روى V•D دانش آموز پِّر مقطع متوسطه

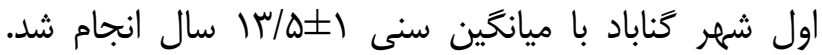

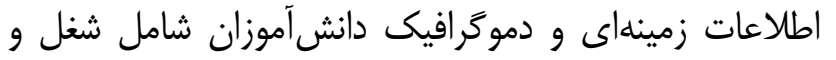
سطح تحصيلات والدين در جدول يك ارائه شده است.
كليـه گويهها بـر اساس طيف ليكرت ه درجهاى (ه =خيلى از

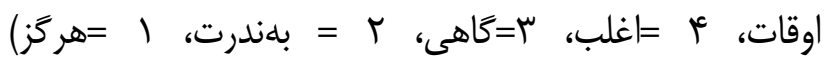

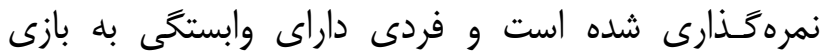
رايانهاى تشخيص داده مىشود كه حداقل يك ملاكى را در

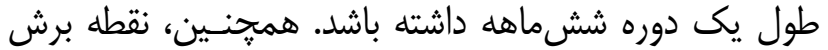

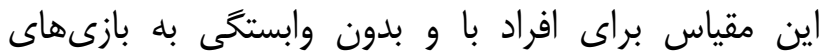

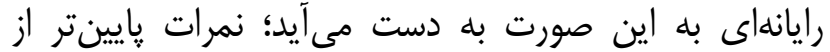

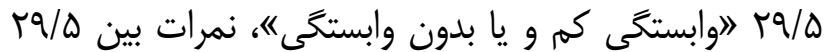

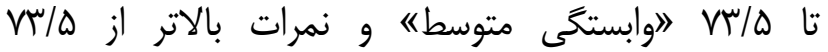
"وابستخى شديد" به بازىهاى رايانهاى دارند (19).

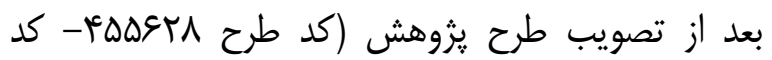
اخلاق IR.BUMS.REC.1397.124)، از معاونت تحقيقات

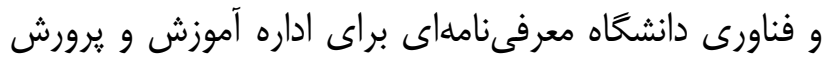

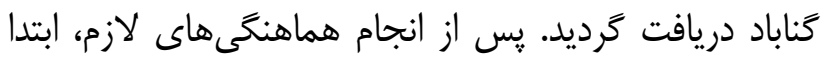

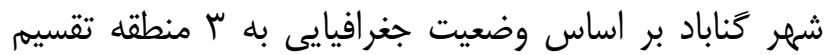

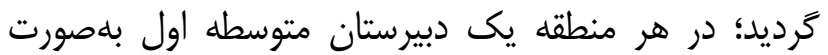

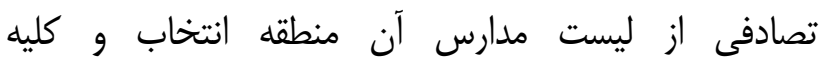

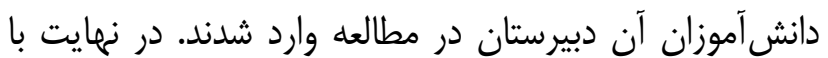

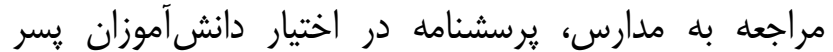
جدول ا - توزيع فراوانى سطح تحصيلات و شغل والدين دانش آموزان يسر مورد مطالعه

\begin{tabular}{|c|c|c|c|}
\hline درصد & فراوانى & \multicolumn{2}{|c|}{ نام متغيّر } \\
\hline $11 / 1$ & q. & ابتدايى & \multirow{4}{*}{ سطح تحصيلات يدر } \\
\hline $\mathrm{W} / \mathrm{V}$ & 90 & راهنمايى & \\
\hline$r \Gamma / \Delta$ & ITE & متوسطه & \\
\hline Fa & THA & دانشخاهى & \\
\hline $\mid Q / \Lambda$ & $\wedge$. & ابتدايى & \multirow{4}{*}{ سطح تحصيلات مادر } \\
\hline $18 / 9$ & $\wedge f$ & راهنمايى & \\
\hline$r \Delta / \Lambda$ & |r| & متوسطه & \\
\hline 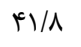 & TIT & دانش & \\
\hline$r q / 1$ & $|Q|$ & كارمند & \multirow{4}{*}{ شغل يدر } \\
\hline$r V / \Lambda$ & $|f|$ & مشاغل كارگرى & \\
\hline ir & 91 & كاسب & \\
\hline$r \cdot / \kappa^{c}$ & IDF & ساير & \\
\hline 99 & ra. & خانهدار & \multirow{3}{*}{ شغل مادر } \\
\hline$r r / D$ & 111 & كارمند & \\
\hline$N / \Delta$ & re & مشاغل خانكَى & \\
\hline
\end{tabular}


ميزان نظارت والدين بر كارهاى دانشآموزان بلهترتيب:

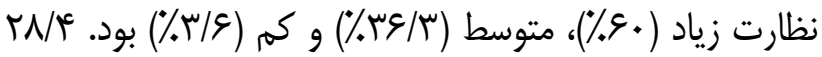

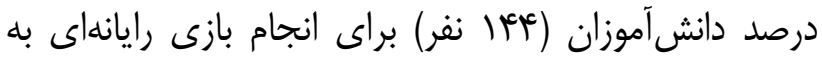

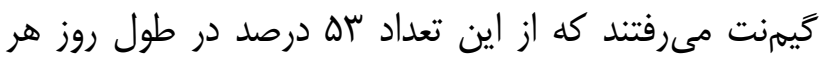

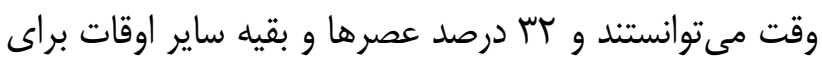

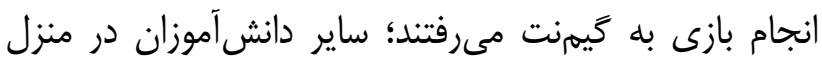

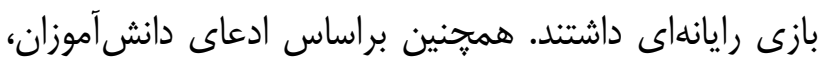

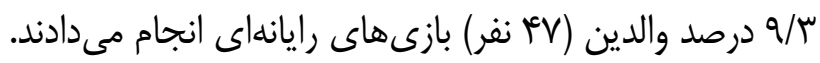

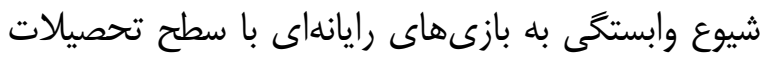

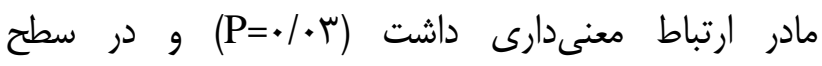
تحصيلات راهنمايى، بالاتر از ساير سطوح بود. وابستكى به آنه

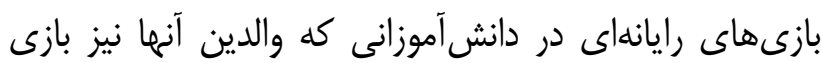

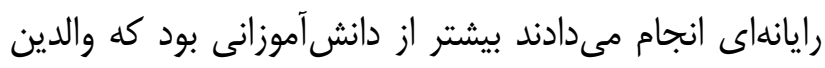

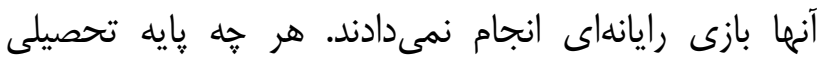

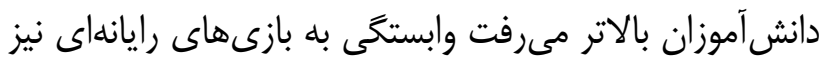

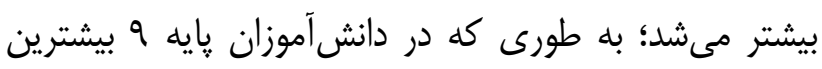
ميزان وابستخى به بازى رايانهاى مشاهده شد. على إغهم اينكه

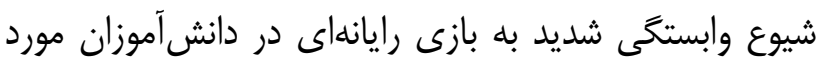

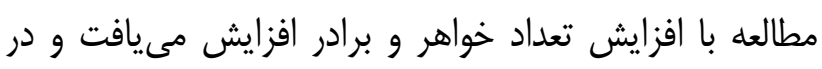

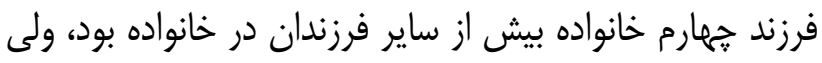

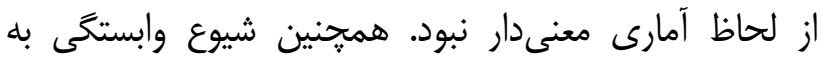

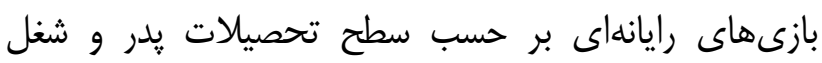

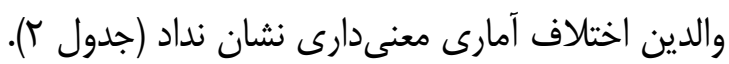

ميانكين ساعات بازى با رايانه در هفته در دانشآموزان

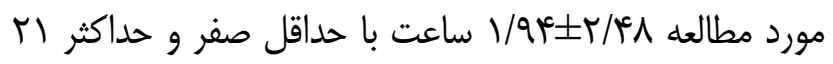

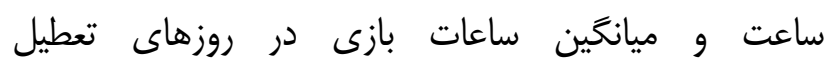
ك

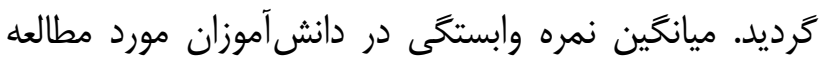
تراسا

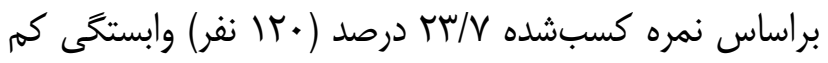

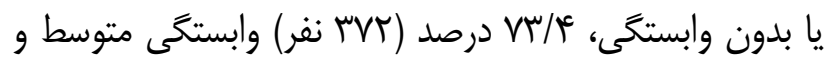

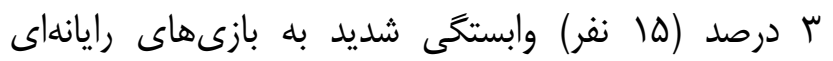

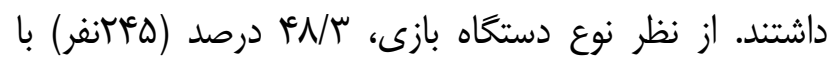

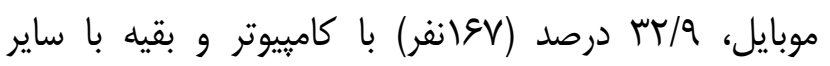
وسايل، بازى مى كردند.

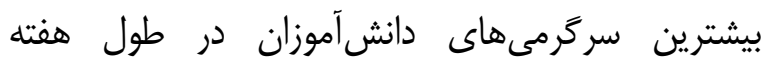

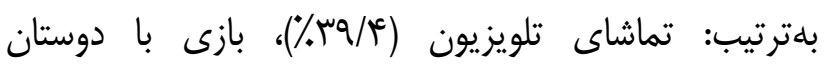

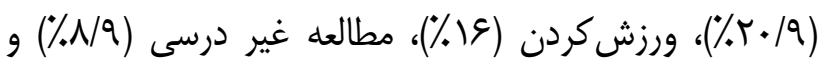

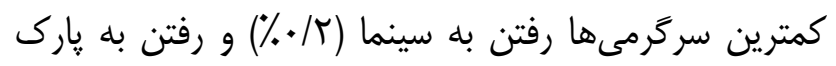

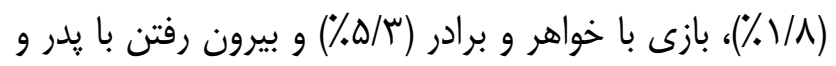

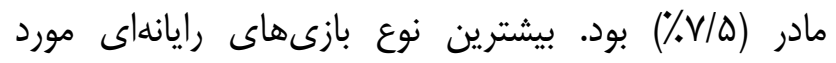

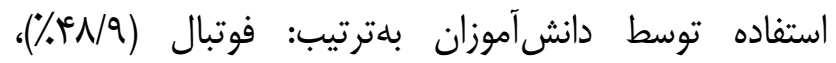

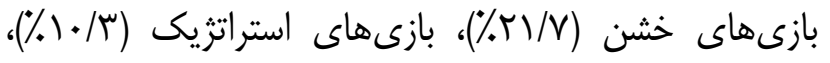

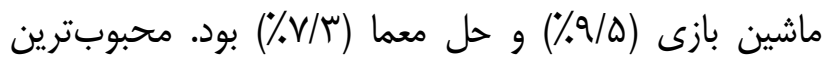

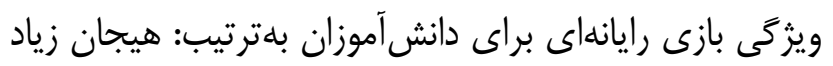

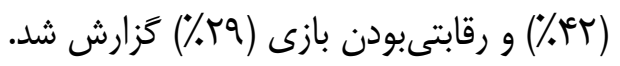


جدول r- مقايسه شيوع وابستَّى به بازىهاى رايانهاى برحسب متغير هاى دموَّر افيك دانش آموزان مورد مطالعه

\begin{tabular}{|c|c|c|c|c|c|}
\hline \multirow{3}{*}{ آزمون دقيق معنى فيشرى } & \multicolumn{3}{|c|}{ وضعيت وابستكى } & & \multirow{3}{*}{ 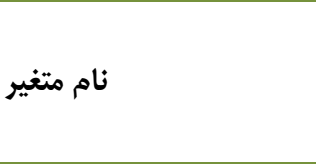 } \\
\hline & وابستكى شديد & وابستكى متوسط & وابستكى كم & & \\
\hline & (درصد) فراوانى & (درصد) فر اوانى & (درصد) فراوانى & & \\
\hline \multirow{4}{*}{.199} & $1(1 / v)$ & $\boldsymbol{r} \wedge(\Lambda \cdot)$ & $川(1 N / T)$ & ابتدايى & \multirow{4}{*}{ سطح تحصيلات بِر } \\
\hline & $F(\mathcal{E} / T)$ & $g x\left(g V / T^{c}\right)$ & $T V\left(T N / T^{*}\right)$ & راهنمايى & \\
\hline & $\Gamma(T / \mathcal{T})$ & $9 \Delta(V \varepsilon / \varepsilon)$ & $r \varepsilon(Y))$ & متوسطه & \\
\hline & $V(r / 1)$ & $19 \Delta(V T / F)$ & $\Delta F(T F / \mathcal{G})$ & دانشَاهي & \\
\hline \multirow{4}{*}{$\cdot / \cdot \mu^{*}$} & $\cdot(\cdot)$ & $\Delta V(Y / r)$ & $r \mu(T N / \Lambda)$ & ابتدايى & \multirow{4}{*}{ سطح تحصيلات مادر } \\
\hline & $F(\mathcal{F} / \Lambda)$ & $V \cdot(\Lambda \mu / \mu)$ & $1 \cdot(11 / 9)$ & راهنمايى & \\
\hline & $s(x / 9)$ & $9 \Delta(V T / \Delta)$ & $r \cdot(K r / Q)$ & متوسطه & \\
\hline & $\Delta(T / F)$ & $10 \cdot(V \cdot / 1)$ & $\Delta V(r \varepsilon / Q)$ & دانشكاهي & \\
\hline \multirow{4}{*}{ 要 } & $\varepsilon\left(f^{c}\right)$ & $\| \Gamma(V F / \Lambda)$ & $r(r(Y / T)$ & كارمند & \multirow{4}{*}{ شغل يدر } \\
\hline & $\cdot(\cdot)$ & $1.9(V V / T)$ & $r Y(Y r / v)$ & مشاغل كارَّى & \\
\hline & $r(\mathcal{F} / q)$ & $\operatorname{cr}(V \cdot / D)$ & $1 D(K F / \bar{G})$ & كاسب & \\
\hline & $q(5 / 9)$ & $1 \cdot V(\xi q / \Delta)$ & FI (TE/G) & ساير & \\
\hline \multirow{3}{*}{. / 1 S } & $I r(r / F)$ & $r \Delta \Delta(V Y / q)$ & $\Lambda \mu(\Gamma \mu / V)$ & خانه دار & \multirow{3}{*}{ شغل مادر } \\
\hline & $r(1 / \Lambda)$ & $\wedge \vee(V \varepsilon / \Gamma)$ & $r \Delta(r) / q)$ & كارمند & \\
\hline & $I(T / \mu)$ & $\Gamma \cdot(99 / \wedge)$ & $I T(T V / Q)$ & مشاغل خانكى & \\
\hline \multirow{2}{*}{$\leq . / \cdot 1^{*}$} & $g(I r / \Lambda)$ & $r q(V q / q)$ & $\Delta(1 \cdot / 9)$ & بلى بلى & \multirow{2}{*}{ بازى والدين با كامييوتر يا } \\
\hline & $q(Y)$ & ( & $\| F(Y \Psi / \Lambda)$ & خير & \\
\hline \multirow{3}{*}{$\cdot / M F$} & $f(I / V)$ & $|V|(V T / V)$ & 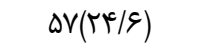 & $\leq r$ & \multirow{3}{*}{ تعداد خواهر و برادر } \\
\hline & $V(\Gamma / \mathcal{Y})$ & $\operatorname{lrV}(v \cdot / 9)$ & $\Delta \cdot(\Gamma \Delta / \Lambda)$ & r & \\
\hline & $F(c / 9)$ & sf(Vq) & $\|(19)$ & $\geq \varphi^{c}$ & \\
\hline \multirow{3}{*}{.1 .9} & $F(I / V)$ & $\operatorname{IV}(V T / F)$ & $\Delta q(\Gamma+q)$ & اول & \multirow{3}{*}{ رتبه فرزند در خانواده } \\
\hline & $V(\Gamma / \Gamma)$ & $|\&|(V Y / Q)$ & $\Delta F(\Gamma E / \Gamma)$ & دوم يا سوم & \\
\hline & $r(N / T)$ & $w V(V / /)$ & $V(1 F / 8)$ & $\geq r^{k}$ & \\
\hline \multirow{3}{*}{$\cdot 1 \cdot 0^{*}$} & $\Gamma(1 / \Lambda)$ & $111(99 / 9)$ & $\Delta \Gamma(\Psi \bar{r} / \Psi)$ & هفتم & \multirow{3}{*}{ پايه تحصيلى } \\
\hline & $\Delta(Y / Q)$ & Irr(VG/V) & $r \Delta(r \cdot / r)$ & هشتم & \\
\hline & $V(F / 1)$ & $\operatorname{lrq}(v \varepsilon / r)$ & 足 & نهم & \\
\hline
\end{tabular}

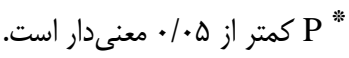

مختلفى است كه انجام تحقيقات بيشتر براى درك بهتر اين

در هند سال اخير، رايانه و بازىهاى رايانهاى بلتدريج ريديده مورد نياز است. مطالعه حاضر با هدف تعيين ميزان

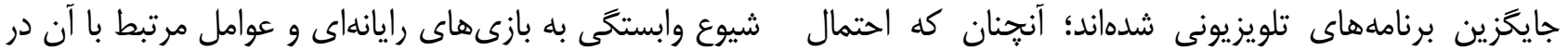

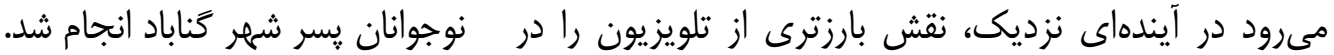

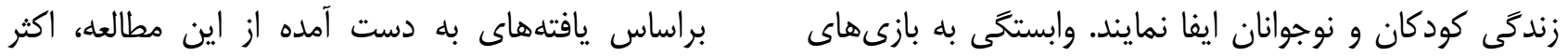

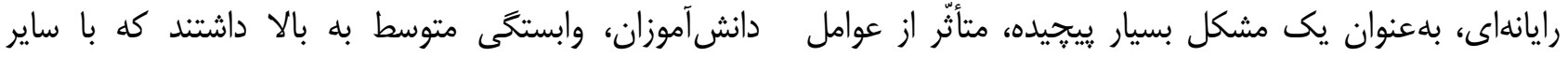


دانشآموزانى بود كه والدينشان بازى رايانهاى انجام نمىدادند؛ اين نتيجه بيانكر اين مطلب است كه فرزندان ازئ إنان

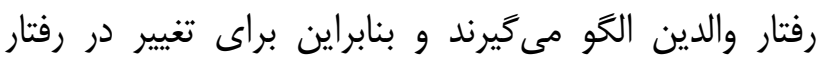

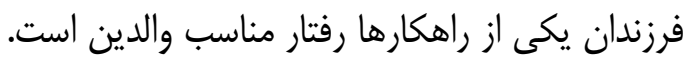
در مطالعه حاضر بيشترين نوع بازى رايانهاى مورد استفاده

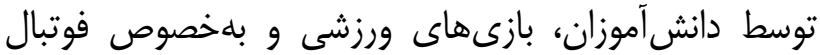

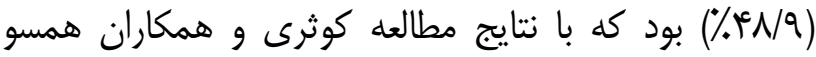

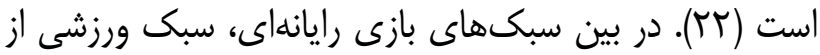

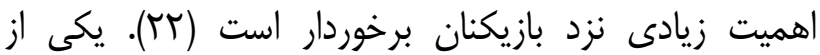

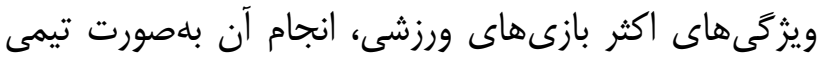
است و محبوبترين بازى در اين سبك بازى فوتبال مى إباشدا.

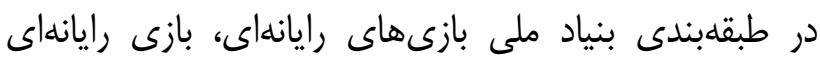

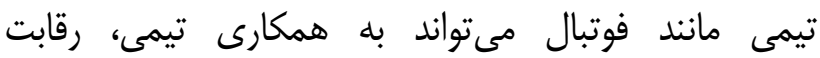

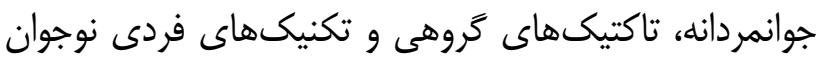
كمى نمايد. نتايج مطالعه باقرى و همكاران دانشآموزانى كه به بازىهاى آناين كَّترده تيمى علاقهائد

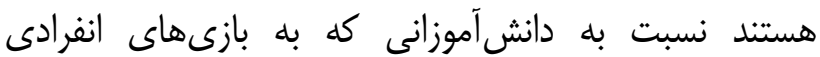
علاقهمندند، از خلاقيت بيشترى برخوردارند (سب)؛ بنابراين

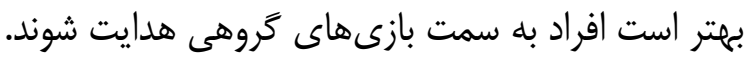

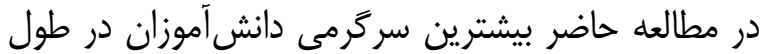

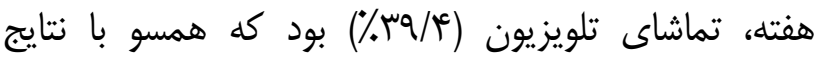

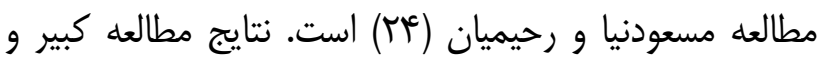

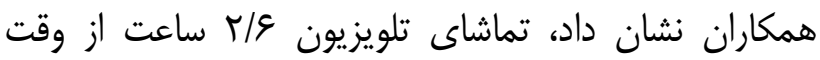

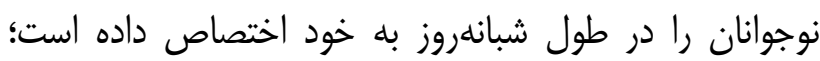

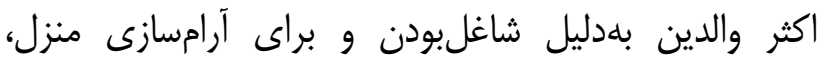

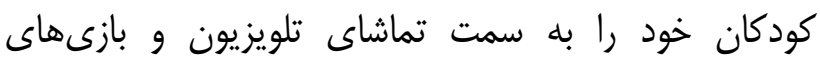

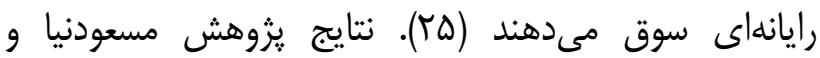
رحيميان مؤيد اين مطلب است كه اكثر والدين (وN/V/V) محدوديتى براى فرزند خود در منزل براى تماشاى تلويزيون و التئ

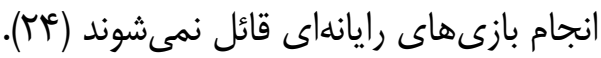

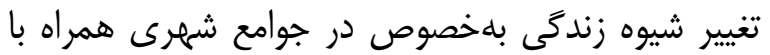

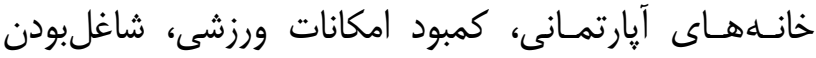

مطالعات انجامشده در كشور از جمله مطالعه كوهى (1) و و كوروش امينى و همكاران (IT) همسو است و مؤيّد اين دمان

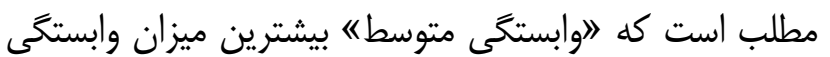
را به خود اختصاص داده است. در مطالعات مختلف، شيوع بازىهاى رايانهاى در ميان

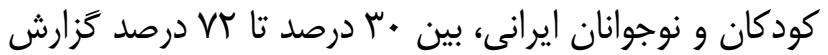

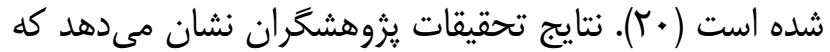

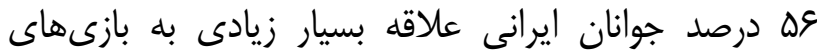

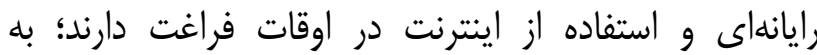

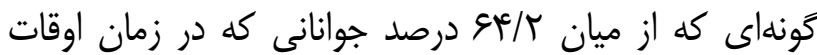

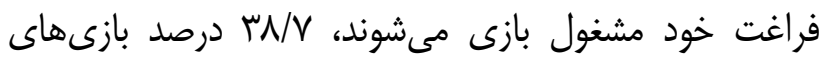

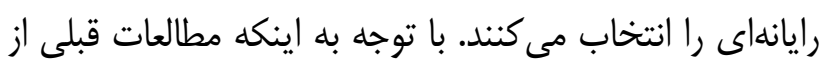

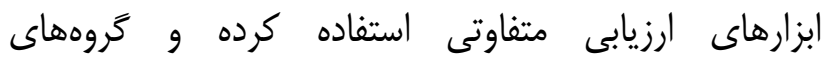

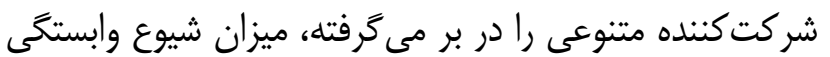

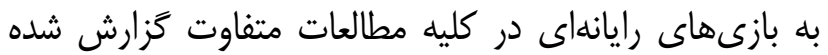

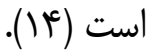
در مطالعه حاضر محبوبترين ويزگى بازىهاى رايانهاى

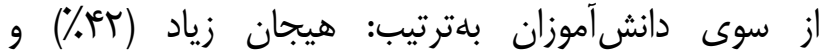

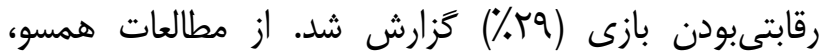
مطالعه امينىمنش و همكاران است كه در آن رقابت و مقابله

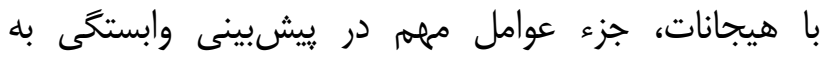

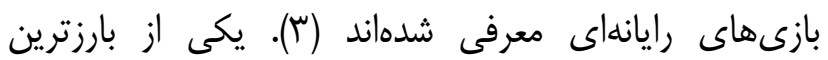

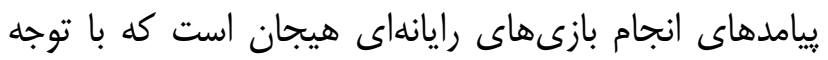

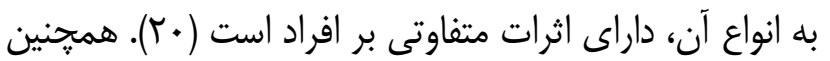

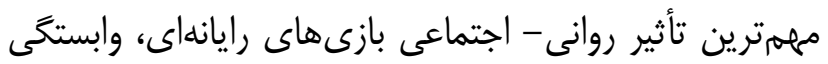

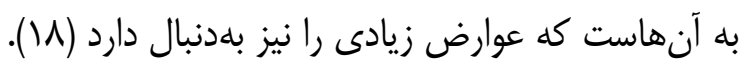
در اين مطالعه مشخص شد كه بَ درصد بازيكنان رايانه

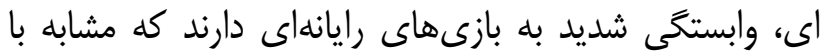

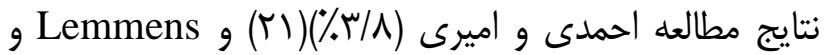

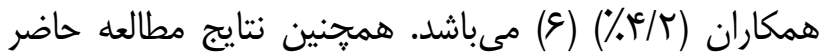

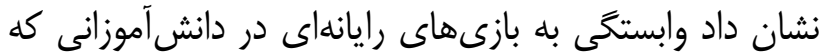

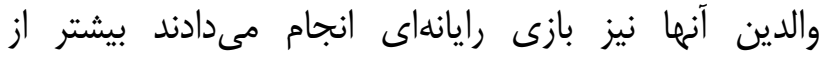


والدين و در دسترسبودن انواع سرگرمىهـا سبب شده تا جايخزينهاى مناسبتر و جذابتر مانند: شنا، اسكيت،

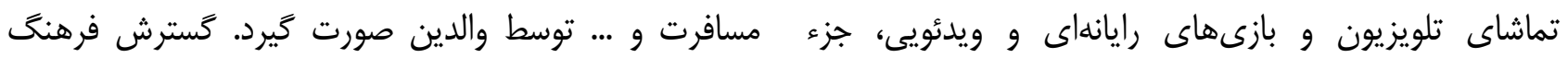

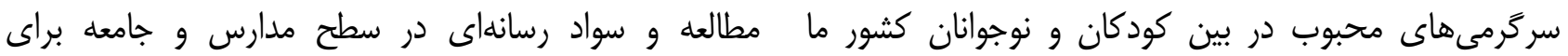

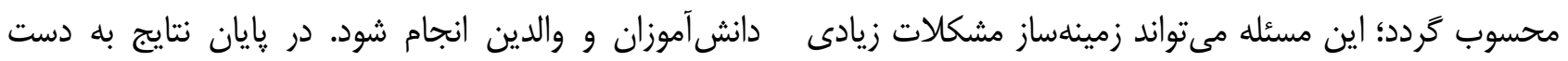

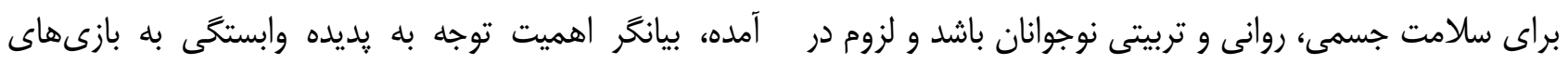

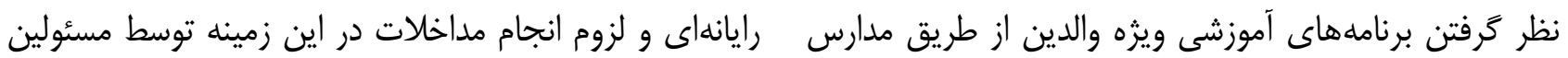

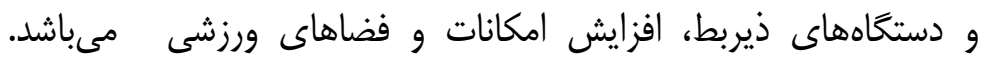

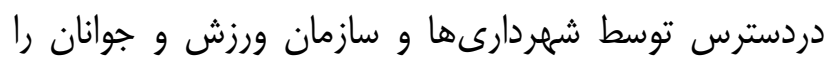

\section{تقدير و تشكر} دوجندان مىنمايد.

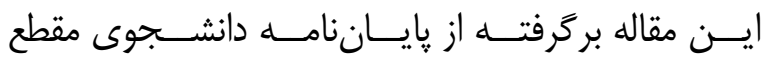

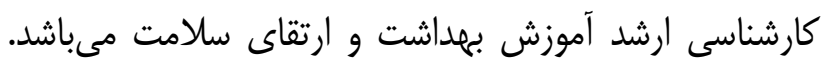

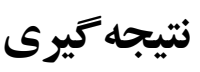

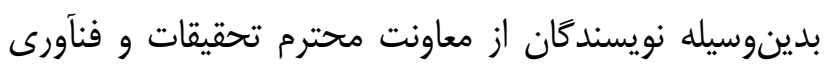

نتايج بهدست آمده از اين مطالعه نشان داد كه لاوابستخى

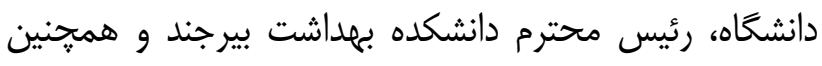

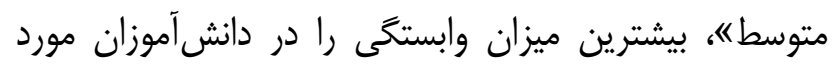

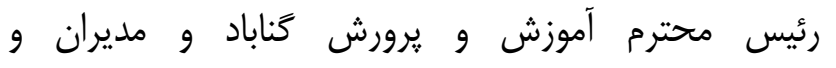

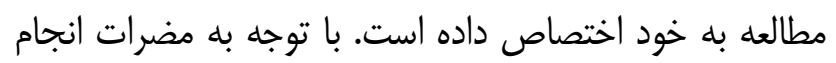
دانشآموزان ارجمند مدارس متوسطه اول شهرم كناباد كه مديس بعرويه بازىهاى رايانهاى بر سلامت نوجوانان و ساير نتايج

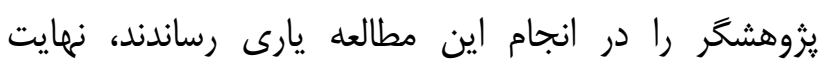

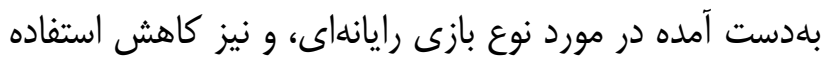
قدردانى و سياس را به عمل مى آورند. از وسايل ورزشى و تفريحى سالم و وابستخى بيشتر

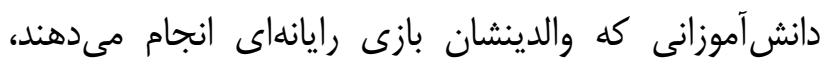

تضاد منافع

نويسندًان مقاله اعلام مىدارند كه هيج گَونه تضاد

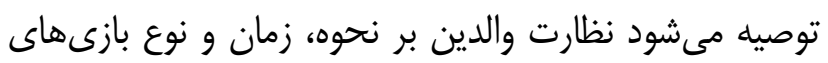

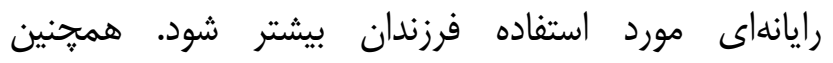
منافعى در يزوهش حاضر وجود ندارد.

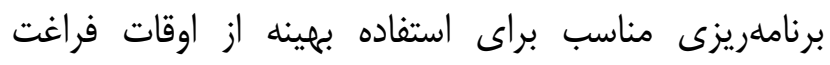

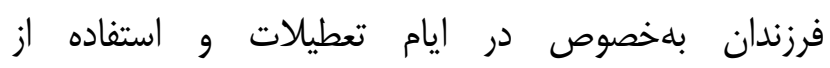

1- Grüsser SM, Thalemann R, Griffiths MD. Excessive computer game playing: evidence for addiction and aggression? Cyberpsychol Behav. 2007; 10(2): 290-2. doi: 10.1089/cpb.2006.9956.

2- Amory A, Naicker K, Vincent J, Adams C. The use of computer games as an educational tool: identification of appropriate game types and game elements. Br J Educ Technol. 1999; 30(4): 311-21. doi: 10.1111/1467-8535.00121

3- Aminimanesh S, Nazari A, Farzad V, Khanzadeh M. The Role of Psychological Motivations in Online Gaming Addiction among Adolescents. Journal of Health and Care. 2017; 19(3): 147-57. [Persian]

4- Saunders JB, Hao W, Long J, King DL, Mann K, Fauth-Bühler M, et al. Gaming disorder: Its delineation as an important condition for diagnosis, management, and prevention. J Behav Addict. 2017; 6(3): 271-9. doi: 10.1556/2006.6.2017.039.

5- Zamani E, Chashmi M, Hedayati N. Effect of addiction to computer games on physical and mental health of female and male students of guidance school in city of Isfahan. Addiction \& Health. 2009; 1(2): 98-104. [Persian]

6- Lemmens JS, Valkenburg PM, Peter J. Development and validation of a game addiction scale for adolescents. Media Psychol. 2009; 12(1): 77-95. doi: 10.1080/15213260802669458 
7- Farmanbar R, Tavana Z, Estebsari F, Atrkar RZ. The relationship between playing computer games with Aggression among middle school students in the city of Rasht in 2013. Iran J Health Educ Health Promot. 2013; 1(3): 57-66. [Persian]

8- Aarseth E, Bean AM, Boonen H, Colder Carras M, Coulson M, Das D, et al. Scholars' open debate paper on the World Health Organization ICD-11 Gaming Disorder proposal. J Behav Addict. 2017; 6(3): 267-70. doi: 10.1556/2006.5.2016.088.

9- Moshirian Farahi M, Goodarzy N, Tabibi Z, Zarif golbaryazdi H. Mothers' Experiences of Children's Tendency to Computer Games: a Qualitative Study. Iran J Health Educ Health Promot. 2017; 5(3): 173-81. [Persian] doi: 10.30699/acadpub.ijhehp.5.3.173

10- Sotudeh H, Rashidi K. Consequences of information technology on mental, ethical and social health. Health Inf Manage. 2013; 10(2): 1-16. [Persian]

11- Seyed Hosseini SMA, Nejadi P, Nasiri H. Perceived Values Patterns for the Players of the Different Digital Games Platforms. Journal of Iranian Cultural Research. 2019; 12(1): 1-25. [Persian]

12- Amini K, Amini Ae, Yaghoubi M, Amini D. High school students playing computer games; 2008.

13- Wittek CT, Finserås TR, Pallesen S, Mentzoni RA, Hanss D, Griffiths MD, et al. Prevalence and predictors of video game addiction: A study based on a national representative sample of gamers. Int J Ment Health Addict. 2016; 14(5): 672-86. doi: 10.1007/s11469-015-9592-8

14- Ferguson CJ, Coulson M, Barnett J. A meta-analysis of pathological gaming prevalence and comorbidity with mental health, academic and social problems. Journal of Psychiatric Research. 2011; 45(12): 1573-8. doi: 10.1016/j.jpsychires.2011.09.005

15- King DL, Delfabbro PH, Griffiths MD. The role of structural characteristics in problematic video game play: An empirical study. Int J Ment Health Addiction. 2011; 9(3): 320-33. doi: 10.1007/s11469-010-9289-y

16- Koohi K. Youth And New Media: The Study Of The Students Addiction To Computer Games And Its Related Factors. Journal of Culture-Communication Studies. 2015; 15(28): 111-32. [Persian]

17- Niazi M, Shafaei E, Hasanzadeh Z. The Relationship between Addiction to Computer Games and Isolation of adolescents: A Case Study of Junior High School Students in Kashan in 1395. Journal of Iran Cultural Research. 2019; 12(1): 85-108. [Persian] doi: 10.22035/jicr.2019.380

18- Vafaeenajar A, Masihabadi M, Moshki M, Ebrahimipour H, Tehrani H, Esmaily H, et al. Determining the theory of planned behavior's predictive power on adolescents' dependence on computer games. Iran J Health Educ Health Promot. 2015; 2(4): 303-11. [Persian]

19- Abedini $\mathrm{Y}$, khozani $\mathrm{MH}$. Investigating validity and reliability of addiction to computer games Scale in adolescent students. Psychoscience. 2012; 11(43).

20- Taghavi Jelodar M, Poursharifi H, Nazari MA, Shahrokhi H. The effects of computer games with high (call of duty) and low (angry birds) stimulating rate on the arousal levels in boys. Research in Psychological Health. 2017; 11(1): 3948. [Persian]

21- Ahmadi J, Amiri A, Ghanizadeh A, Khademalhosseini M, Khademalhosseini Z, Gholami Z, et al. Prevalence of addiction to the internet, computer games, DVD, and video and its relationship to anxiety and depression in a sample of Iranian high school students. Iran J Psychiatry Behav Sci. 2014; 8(2): 75-80.

22- Kosari M, Aghazadeh M, Seyed Hosseini SMA. Measurement the attitude of the Iranian people about computer games: comparison the attitude of people were studied in age 7-40. Journal of Culture-Communication Studies. 2018; 19(41): 91-120. [Persian] doi: 10.22083/jccs.2018.98854.2261

23- Bagherikerachi A, Sadeghi S, Razmjoo MM. Comparing the Creativity of Students interested in Computer Games by Style, History and Hours of Play. Educ Strategy Med Sci. 2019; 11(6): 20-5. [Persian] doi: 10.29252/edcbmj.11.06.03

24- Masoudnia E, Pourrahimian E. Impact of computer game on incidence of behavioral disorders among male elementary school students. Journal of Applied Sociology. 2016. 27(3): 117-34. doi: 10.22108/jas.2016.20501

25- Kabir K, Tizvir A, Hadian S, Moslemkhani Z. A Survey on the Relation between the Rate of Watching and Playing Computer Game and Weight Disorder Regarding first Grade Students in Elementary School in Karaj in 2012. Alborz Univ Med J. 2013; 2(4): 211-6. [Persian] doi: 10.18869/acadpub.aums.2.4.211 